\title{
Ethno Medicinal Plants used by Tribal Communities in Vindhya region of Rewa and Sidhi District of Madhya Pradesh, India
}

\author{
1. Rajendra Prasad Bharti, 2.Abhilasha shrivastava,3. jagjeevan ram choudhary 4. Asha Tiwari. 5. N. K. Soni \\ Department of Environmental Biology A.P.S. University Rewa (M.P.) 486003 \\ Department of Botany \& Biotechnology Govt. Model science College Rewa (MP) 486003 \\ Department of Zoology, govt. PG. College Pipariya (MP) India \\ Department of Economics Govt. Geetanjali Girls College Bhopal (M.P.) India 462001
}

\begin{abstract}
The present study deals with the Ethno-medicinal plants used by tribal communities in Vindhya region of Rewa and Sidhi district of Madhya Pradesh India. An ethno medicinal survey was carried out the use of medicinal plants in Vindhya region, the information was gathered from Kol and goand tribes using an integrated approach botanical collections, group discussion and interview with questionnaire during 2012-13. Among 50 informants interviewed, 10 were tribal practitioners. A total of 26 Taxa belonging to 25 genera and 16 families are documented. In most of case, fresh parts of the plants was used for the prepararation of medicine. These tribal people still depend on the medicinal plants to cure their diseases and disorders in Vindhya forest region. The documented ethno medicinal plants were mostly used to cure wound infections, skin infections stomachache, fever, cough, diabetes, diuretics, diarrhea, eye infections and general weakness.

Key words: Ethno medicine, Medicinal plants, Kol and goand tribe.
\end{abstract}

\section{Introduction}

Traditional medicine widely used the home of tribals and forest dwellers. More than $30 \%$ of the population consists of the tribal people with immense traditional knowledge. Traditional knowledge often includes practices based on observations. Multifarious uses of plants among multiethnic societies are all practice based observations. Study of traditional or folk medicines of tribals is called ethno medicine. A review of past literature on ethno botany indicates that sufficient research work has been done in various part of India. Traditional medicine and ethno botanical information play an important role in scientific research among the medicinal plants used in Ayurvedic medicines for their therapeutic action; some of these have been thoroughly investigated. Central India is known for its richness of medicinal flora. Vindhyanchal, Aravali ranges, Bailadilla, Hills, khurchel valley Kanger Reserve, and Amerkantak, pachmarhi and patalkote areas. Tropical forests which are rich in biodiversity. The present communication deals with the ethno medicinal plants which are used by tribal people of west Rewa district of Madhya Pradesh, India. Topographically Vindhyan region is situated centrally in Northern part covered with Malawa Pathar scabs and Southern part with Satpura hill ranges4. Geographically, Rewa district is situated between $23^{\circ} 10^{\prime}$ and $25^{\circ} 12^{\prime}$ north latitudes and $78^{\circ} 5^{\prime}$ and $82^{\circ} 18^{\prime}$ east longitudes. The Rewa district region was formerly known as vindhyan kagari. It is situated on the bank of Bihar River. The vegetation is the typical of arid regions with thorny trees like babul, soya bean, wheat, .dhan, arhar, and juwar are main crops of this area. It is famous for the White Tiger and made Supadi toys production. The district is divided into 06 Tehsils, 1407 Villages and it has 23, 63744 population and the district of Sidhi is divided in 05 Tehsil and it has 11, 26515. About $40 \%$ of the population consists of tribal people, Kol, Bhilala, Barela, Tadvi, Banjara, Gond, and Mankar are most common tribes. Tribal communities have an intricate relationship with their surrounding vegetation. In the study, emphasis has been laid on plants species, it would also strengthen the credibility of plants, which are used at many regions for the same purpose, i.e. the collected information not only shows that many preparations are made from single plant but rarely mixture of several plants is used. Majority of the predations are taken orally and applied on the skin. In the studied area, many people still have faith in the herbal remedy which plays an important role in the life of these communities.

\section{Material And Methods}

The present study was done during 2012-2013. The information was collected from various tehsil of Rewa and Sidhi district (Sirmour, Tyother, Gurh, Raipur, Karchuliyan, Maughanj, Hanumana, Shihawal, Churahat, Rampur Naikeen, Maghauli, and Kushmi). The information was gathered through questionnaire method and discussions with tribal, local healers. The herbarium sheets were prepared and identification was done following the standard literature. Plant collection carried out by standard method. Identification of plants done with the help of flora and other Taxonomic literature Information was gathered through questionnaire method and discussions with tribal, local healers. Plant keeps between fold of blotting paper. Dried the plant specimens by herbarium press Preserved Plant specimen Standard literature was followed. Plant survey carried 
out by well planned schedule. All habitats of the study area surveyed carefully. Ethno medicinal data were collected by the suggested methodology. The data including local name mode of preparation, medicinal uses, parts used were collected using interview, questionnaire, collecting samples and dissections with the practitioners. Nomenclature of the specimens deposited in the Pharmacology and Pinnacle Biomedical Research Institute (PBRI) Bhopal.

\section{Result And Discussion}

During investigation medicinal plant uses of many as reveled in all 26 Taxa belonging to 25 genera and 16 families it is evidence from the data given in table 1 village of Rewa and Sidhi district of Madhya Pradesh India. Important Taxa which are used by the tribal people are Achyranthes aspera, Ageratum conyzoides, Butea monosperma, Calotropis procera, Datura metal, Clitoria ternatea, Tamarindus indica and others. The above results were compared with ancient literature and recently published research papers and journals. These useful plants need protection and more cultivation in the present context, so that the tribal people may more be benefited and our valuable flora may also survive. Ethno medicinal Wealth, which are used by local inhabitants for various aliment including cough joint pain, cholera, urinary, trouble kidney, stone diabetes, fever jaundice, syphilis male sterility and gonorrhea, diseases of liver skin and stomach (nayak et al.2000,Sharma 1990). These medicinal plant are fold to the dealers are crude drugs for which they happen to be main economic sources of the tribal people realizing that the plant diversity of rewa and sidhi district is a boon to the tribal people and it is emphasized that the flora should be conserved for future generations and the tribal population should be an encouraged for growing these medicinal plants on a large scale for optimizing their economic conditions there is also an argent need to documents the indigenous knowledge about medicinal plant are existing still two day in Rewa and sidhi district Madhya Pradesh.

TABLE 1:- Medicinal plants used by goand and kol tribs

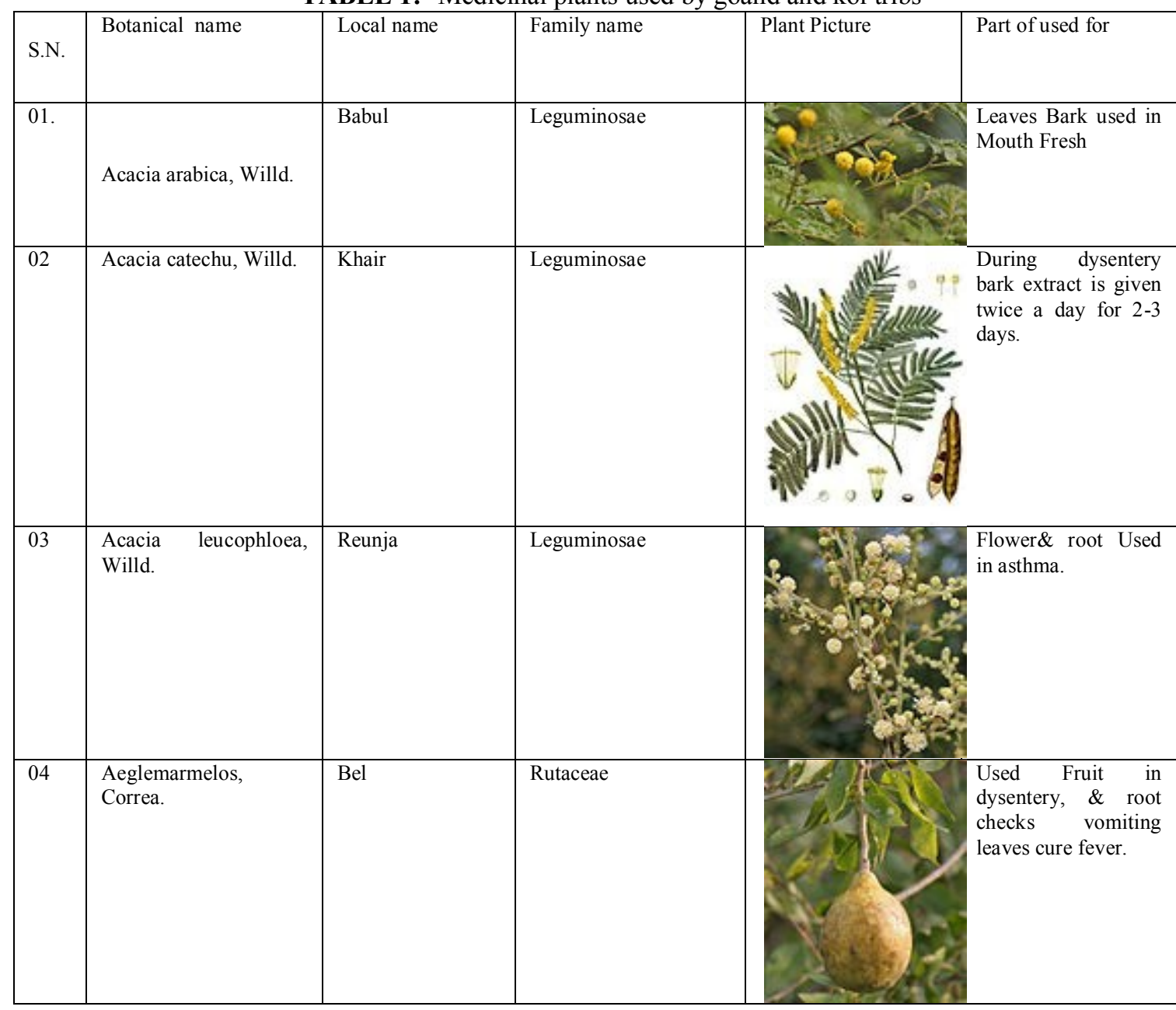




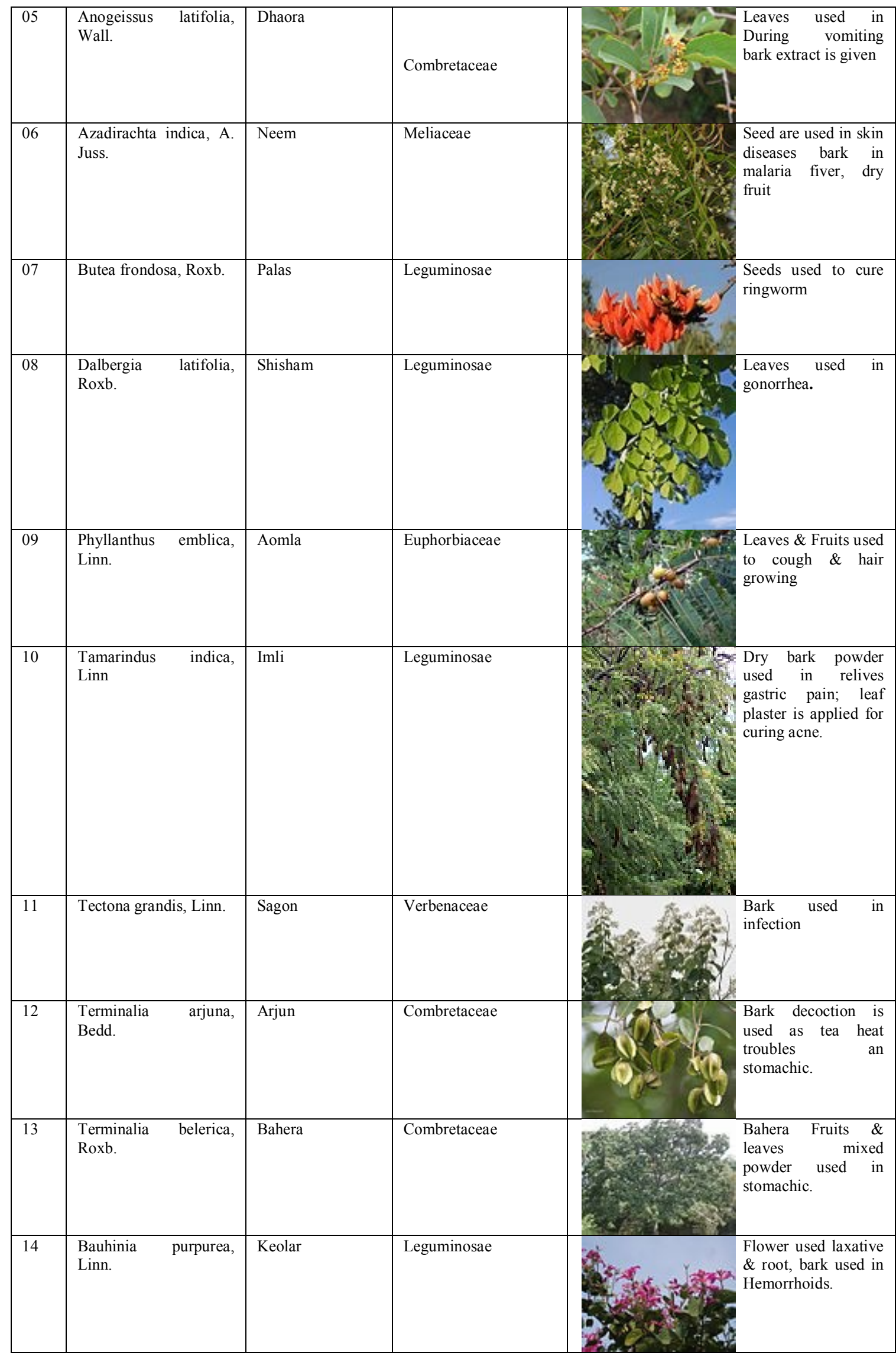




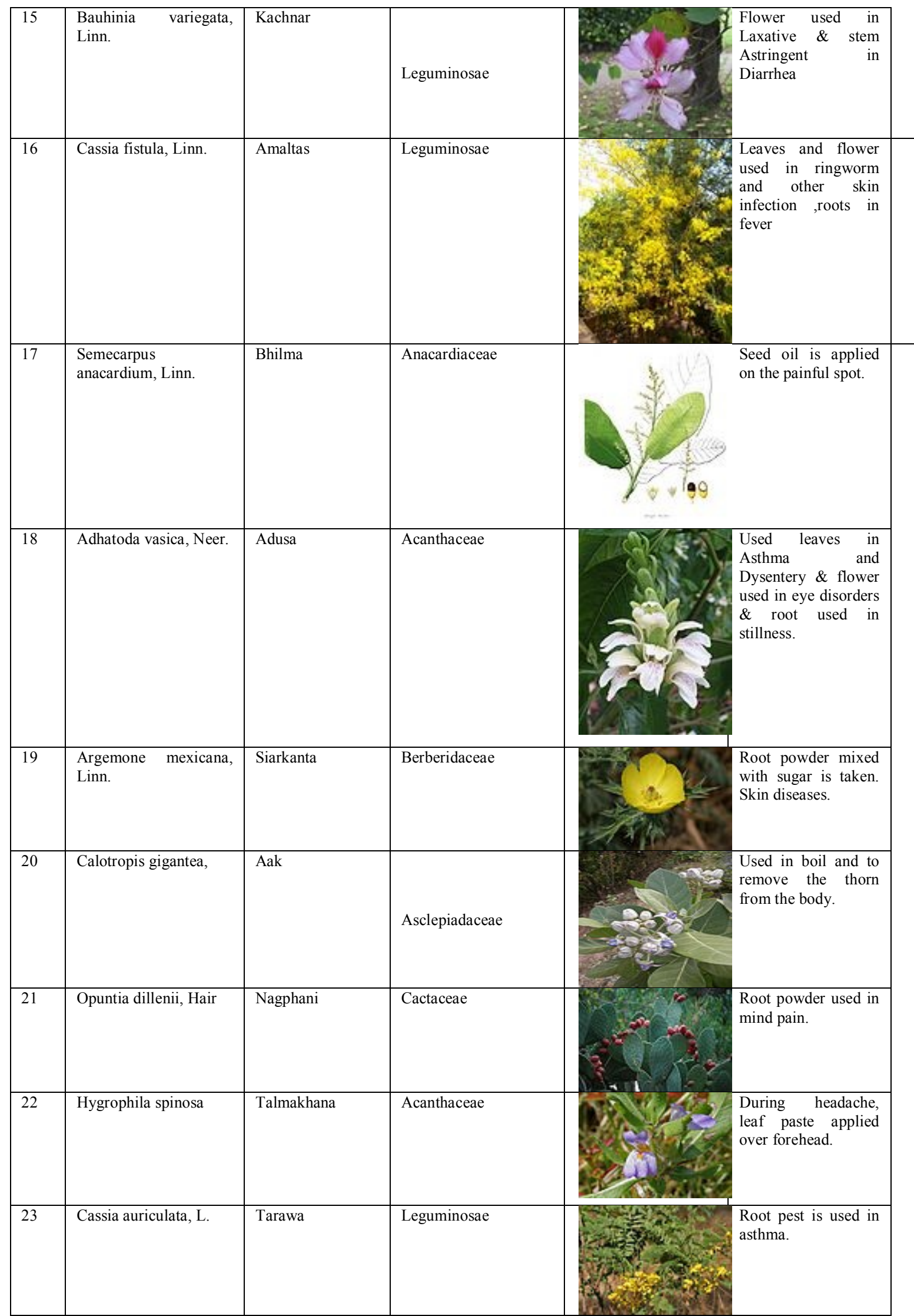




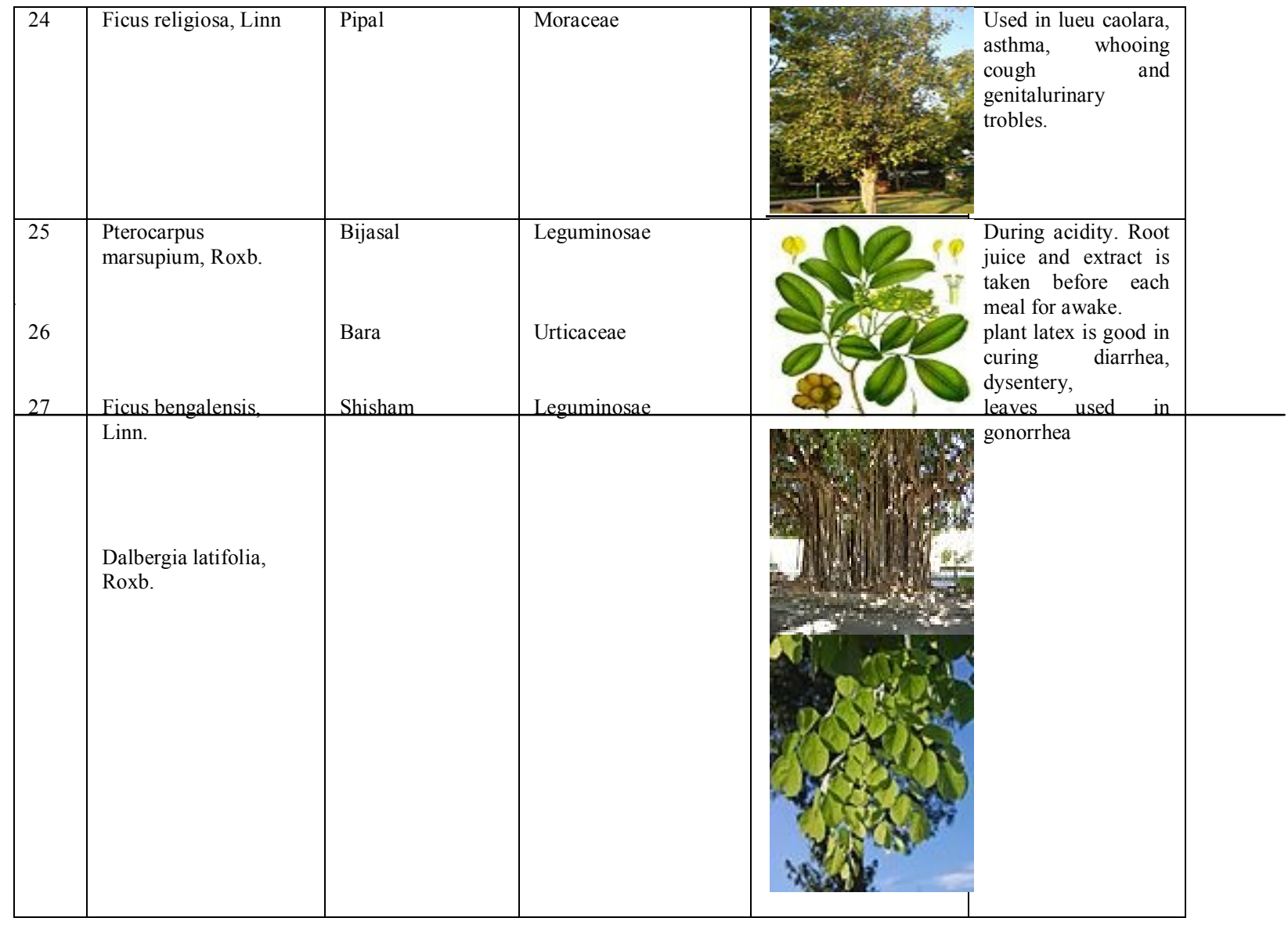

IV. Conclusion

The study concludes that the role of herbal medicine for the treatment of various diseases and disorders among tribe is crucial. They used many different forest plants, weeds, flowers, seeds, bark in their traditional treatment. Beyond documented plants. These people use several other plants for non medicinal purposes. The collection information not only shows that many preparations are made from single plants but rarely mixture of several plants is used. Majority of the preparations are taken orally and applied on the skin. In the studies area, many people still have faith in the herbal remedy which plays an important role in life of these communities

\section{ACKNOWLEDGEMENT:-}

I gratefully acknowledge the help and encouragement I revived from Prof. R.N. Shukla and Prof. (Mrs.) U.K. Chouhan, Department of environmental Biology, A.P.S. University Rewa (m.p.), Prof. (Mrs.) Abhilasha Shrivastava, , Department of Botany and Biotechnology, Govt. Model Science College Rewa (M.P.) and Govt. P.G. College Piparia (M.P.), and Dr. Ravi Uppadhya Dr. Shourabh jain , PBR Institute Bhopal (M.P.). I am al so thank full to the people various tehsil of Rewa and Sidhi district (Sirmour, Tyother, Gurh, Raipur, Karchuliyan, Maughanj, Hanumana, Shihawal, Churahat, Rampur Naikeen, Maghauli, and Kushmi). Who were the main sources of information documented in this work.

\section{Reference}

[1]. Antony G. et.al., Herbs and Indigenous Knowledge of Medicinal Plants used by Saperas community of Khetawas, Jhajjar District, Haryana India, Journal of Ethno bio. And Ethno med, 6, 4 (2010)

[2]. Chopra R. N. Nayar S. L. and Chopra I. C. Glossary of Indian medicinal plants, C. S. I. R. New Delhi (1956) 03 Houghton P.J. and Osibogun T.M., Flowering plant used against Snakebite, J. Ethanopharma, 39(1), 1-29 (1993) - Khetawas, Jhajjar District, Haryana India, Jour. of Ethno bio and Ethno med, 6, (2010). Houghton P.J. and Osibogun T.M., Flowering plant used against Snakebite, J. E03 thanopharma,39(1),

[3]. Cooke T., Flora of the Presidency of Bombay, 1 BSI Calcutta (1957)

[4]. Mahajan S.K. A preliminary survey of the Anthelminitic plants used by the tribal's of west Nimar district, M.P. Plant Diversity Human Welfare and Conservation, 289-292 (2003).

[5]. Jain S.K. and Rao R.R., A Handbook of herbarium methods Today and Tomorrow, New Delhi (1977)

[6]. Kirtikar K.R. and Basu B.D., Indian Medicinal Plants, Vols. I - IV, Lalit Mohan Basu, Leader Road, Allahabad, India, 2793 (1935)

[7]. Kirtikar K.R. and Basu B.D., Indian Medicinal Plants, Vols. I - IV, Lalit Mohan Basu, Leader Road, Allahabad, India, 2793 (1935)

[8]. Mahajan S.K. et.al, a preliminary survey of the Anthelminitic plants used by the tribals of west Nimar district, M.P. Plant Diversity Human Welfare and Conservation, 289-292 (2003) 
[9]. 9.Patil H.M., Ethno botanical Notes on Sapura Hills of Nandurbar District, Maharashtra, India, Res.J.Recent.Sci., 1(ISC-2011), 326$328(2012)$

[10]. Patil Sunil J. and Patil H.M., Ethno medicinal Herbal Recipes from Sapura Hill Ranges of Shirpur Tahsil, Dhule, Maharashtra, India, Res. J .Recent. Sci., 1(ISC- 2011), 333-336 (2012)

[11]. Sainkhediya Jeetendra and Ray Sudip, Preliminary study of flowering plant Diversity of Nimar region, Bioscience Discovery, 3(1), 70-72 (2012)

[12]. Sinha B.K. and Shukla B.K., Synoptic flora of Khargone district Madhya Pradesh-3 Hydrocartitaceae to Poaceae, J. Econ. Tax Bot. 31(1), 120-149 (2009)

[13]. Sinha B.K. and Shukla B.K., Synoptic flora of Khargone district Madhya Pradesh-3 Hydrocartitaceae to Poaceae, J. Econ, Tax Bot. 31(2), 487-642 (2007)

[14]. Sekhar J. et.al. Ethanic information and treatments for Snakebites in Kadapa District of Andhra Pradesh, Life Science Leaflets (12), 368-375 (2011)

[15]. Solanki C.M., Flora of Indore Ph.D. Thesis, D.A.V.V., Indore MP (1984)

[16]. Sekhar J. et.al. Ethanic information and treatments for Snakebites in Kadapa District of Andhra Pradesh, Life Science Leaflets (12), 368-375 (2011)

[17]. Jain S.K., Credibility of traditional knowledge the criterion of multi locational and multiethnic use, Indian J. traditional knowledge, 3(2), 137-153 (2004) 